\title{
EJA: IDAS E VINDAS PARA A ESCOLA
}

\section{EJA: COMINGS AND GOINGS TO SCHOOL}

\author{
Eliane Cabral Oliveira do Nascimento ${ }^{1}$ \\ Mirozete Iolanda Volpato Hanoff ${ }^{2}$
}

\begin{abstract}
RESUMO: O presente estudo tem como foco principal identificar que fatores foram decisivos para que os jovens/adultos não frequentassem a escola em período adequado e o que os motivou a reingressarem na escola. E como objetivos específicos: apontar as causas da desistência da escola desses alunos; destacar os motivos do reingresso na escola; verificar a colaboração da EJA nas interações sociais dos seus alunos egressos. A metodologia de pesquisa consistiu em: entrevista semiestruturada com oito alunos de uma escola de Criciúma, SC. A abordagem do problema apresentou-se com uma caraterística qualitativa. Quanto à Natureza, entende-se que a pesquisa é básica e tendo em vista os objetivos realizou-se pesquisa exploratória e descritiva. Por meio da aplicação do questionário com os alunos que frequentam a EJA foi possível identificar que o "trabalho" foram os principais fatores das idas e vindas destes alunos para a escola.
\end{abstract}

PALAVRAS-CHAVE: Educação de Jovens e Adultos. Escola. Idas e Vindas

ABSTRACT: The main focus of this study is to identify which factors were decisive for young people / adults not attending school at an appropriate time and what motivated them to re-enter school. And as specific objectives: To indicate the causes of the school dropout of these students; Highlight the reasons for re-entry into school; To verify the collaboration of the EJA in the social interactions of its graduating students; The research methodology consisted of analyzing through a semi-structured interview, with closed and open questions and the data approach was through field research, interview script with closed questions. The approach of the study was presented with a qualitative character. As for Nature, it is understood that the research is basic and in view of the objectives, a triad between bibliographic, exploratory and descriptive research was carried out.

KEYWORDS: EJA. School. Return. Students.

\footnotetext{
${ }^{1}$ Acadêmica do Curso de Pedagogia/UNESC. E-mail: elianecabraloliveira@unesc.net.

${ }^{2}$ Orientadora. Graduada em Pedagogia. Especialização em Educação de Jovens e Adultos. E-mail: mvh@unesc.net.
} 


\section{INTRODUÇÃO}

A educação começa a fazer parte da vida das pessoas desde o momento em que nascem, e a cada dia vão aprendendo e descobrindo coisas novas. Porém, como se sabe, nem todos têm a possibilidade de cursar o ensino regular, devido a vários motivos, tais como inadequação do sistema de ensino e condições socioeconômicas desfavoráveis, entre outros. Para atender esta demanda de jovens e adultos sem escolarização, surgiram várias propostas, sendo uma delas a EJA (Educação de Jovens e Adultos), que se propõe a atender este público a quem foi "negado" o direito à educação, no período adequado de seus desenvolvimentos como seres humanos e socioculturais, referente ao ensino fundamental e médio.

A escolha deste tema surgiu ao longo da formação superior, mais especificamente na sexta fase do curso de Pedagogia, na disciplina "Processos Pedagógicos de Jovens e Adultos". O interesse concretizou-se durante o estágio obrigatório da EJA na sétima fase e o mais importante, fazendo um paralelo com a experiência individual desta pesquisadora na Educação de Jovens e Adultos no ano de 2004, na qual atuou como discente.

Acredita-se que esta modalidade de ensino, como espaço de construção de conhecimentos, deve valorizar os saberes trazidos pelos sujeitos, constituídos ao longo de suas histórias, privilegiando o acolhimento e os interesses destes estudantes, jovens ou adultos, que retornam à EJA para dar continuidade a sua escolarização.

Tendo em vista a competitividade do mercado de trabalho nos dias atuais, a formação torna-se cada vez mais indispensável para se disputar uma vaga de emprego nas mais diferenciadas áreas. Dessa forma, a educação tem um papel de grande relevância na construção do processo formativo do sujeito, visto que na escola recebemos os conhecimentos científicos necessários que dão embasamento à vida profissional.

Nesse contexto insere-se a Educação de Jovens e Adultos - EJA, concedendo oportunidade às pessoas que não tiveram a chance de frequentar a escola na idade convencional de investir em sua formação, ampliando os seus conhecimentos, e assim abrindo portas para estudos posteriores, formando o aluno para o mercado de trabalho.

Com este entendimento é que foi escolhido o tema: EJA - Idas e vindas para a escola, cujo problema foi assim formulado: que fatores foram decisivos para que os

Saberes Pedagógicos, Criciúma, v. 3, n³, Edição Especial 2019.- Curso de Pedagogia - UNESC 
jovens/adultos não frequentassem a escola em período adequado a sua idade e o que os motiva a reingressarem na escola? $\mathrm{O}$ estudo tem como objetivo geral: analisar quais fatores foram decisivos para que os jovens/adultos não frequentassem a escola em período adequado e o que os motivou a reingressarem na escola. E como objetivos específicos: apontar as causas da desistência da escola desses alunos; destacar os motivos do reingresso na escola; verificar a colaboração da EJA nas interações sociais dos seus alunos egressos.

O presente artigo foi desenvolvido a partir de pesquisa qualitativa, por meio de entrevistas com alunos da Educação de Jovens e Adultos - EJA, matriculados em uma instituição de ensino pertencente à rede municipal de Criciúma, Santa Catarina, que oferece a EJA no período noturno, a fim de identificar que fatores foram decisivos para que os jovens/adultos não frequentassem a escola em período adequado e o que os motivou a reingressarem à escola para concluir a Educação Básica através da EJA. Compuseram a amostra oito estudantes de ambos os sexos, sendo $85 \%$ do sexo feminino e $15 \%$ do sexo masculino. A pesquisa aconteceu no período de 02 a 09 de abril de 2018. Os entrevistados responderam a oito questões relacionadas ao tema em estudo.

O trabalho foi dividido em duas seções. A primeira trata do surgimento da EJA, expondo, de forma concisa, os processos de transformação e mudanças ocorridos no sistema brasileiro nesta modalidade de educação, ao longo do tempo. Já a segunda faz uma abordagem sobre Educação e sociedade, características dos alunos que procuram a educação de jovens/adultos e o retorno e permanência dos alunos na EJA e encerra o referencial teórico apresentando a escola da EJA como importante espaço de vivência das pessoas e o ser professor nesta modalidade de ensino.

O estudo foi fundamentado em diferentes teóricos, como Cortada (2013), Alarcão (2001), Freire (1996, 2002, 2006), Gadotti (2000) e Lima (1991), bem como em Leis Estaduais e Federais, que tratam sobre o conteúdo pesquisado. E, por fim, as considerações finais e as referências dos materiais utilizados para a realização desta pesquisa. 


\title{
2 EJA: UM RETROSPECTO DO SURGIMENTO AOS DIAS ATUAIS
}

A educação de jovens e adultos no Brasil é tema de discussão desde a época colonial, mas foi no início do século XX, principalmente após 1940, tendo em vista os altos índices apontados de analfabetismo, que passou a ser vista como problema nacional.

De acordo com Cortada (2013, p. 9):

\begin{abstract}
A história da Educação no Brasil começa a se delinear no período colonial com a chegada dos primeiros padres jesuítas, no ano de 1549. Comandados pelo Padre Manoel de Nóbrega, marcam o início da História da Educação no Brasil quinze dias após a chegada no território brasileiro, fundando a primeira escola elementar de Salvador.
\end{abstract}

Ainda no período colonial tanto a escrita quanto a leitura eram incumbências da elite da população metropolitana, pois a economia do país era voltada à exportação, na qual a população carente fazia os trabalhos braçais. Assim, "nesse período, a economia, baseada na exportação de matéria-prima, necessitava muito domínio de técnicas agrícolas e trabalhos manuais, sendo a escrita e a leitura atividades voltadas à elite da população da metrópole" (CORTADA, 2013, p. 9).

No ano de 1808 desembarca no Brasil a família real. Para Cortada (2013, p. 9), “o contorno educacional, com o desembarque da família real no Brasil, em 1808, começou a se expandi".

O Brasil sofria com toda descontinualização política e retrocesso. A falta de registro de experiências, de sistematização e divulgação constituem um dos maiores problemas do Brasil, obrigando o eterno recomeçar" (LIMA, 1991, p. 21).

Assim a educação de adultos só ganhou importância em 1932. Segundo Cortada (2013, p. 10), “a educação de adultos no Brasil ganha maior importância em 1932, quando acontece a Cruzada Nacional da Educação com a finalidade de combater o analfabetismo do país".

No ano de 1949 foi implantado como política educacional o EDA (Educação de Adultos). 
A educação de adultos (EDA) se constituiu como política educacional em meados de 1949, com um discurso pedagógico voltado para a modernização da sociedade. [...] O sistema educacional na época proposto por Capanema correspondia à divisão econômico-social do trabalho. Assim, a educação deveria servir ao desenvolvimento de habilidades e mentalidades, de acordo com os diversos papéis atribuídos às diversas classes ou categorias sociais. (CORTADA, 2013, p. 11).

O analfabetismo passou a ser encarado como um problema gerado pela desigualdade social. Nesse sentido, a educação deveria partir da realidade dos jovens e adultos, de maneira problematizada, levando o educando a assumir-se como sujeito de sua aprendizagem.

Nesse contexto, ganha força as ideias de Paulo Freire (2006), que entende a alfabetização adulta como um sentido de conscientização e leitura de mundo, conquistando assim sua autonomia. Entre os anos de 1961 e 1964 os programas de Alfabetização e Educação Popular pautados pelas ideias de Paulo Freire obtiveram espaço na sociedade brasileira. Porém, em 1964 veio a ditadura militar e com ela o movimento de educação foi extinto:

Em 1963, o ministro da Educação Paulo Tarso, do governo João Goulart, expandiu a experiência para vários estados, organizando Centros de Educação Popular, com adesão de mais de 6 mil educadores voluntários. Com a ditadura militar, em 1964, o Movimento de Educação de Base foi encerrado, sob alegação de teor subversivo. O exílio de Paulo Freire durou 16 anos. (CORTADA, 2013, p. 12).

Em 1969 o governo militar lançou no Brasil o Mobral (Movimento Brasileiro de Alfabetização). Para Cortada (2013, p. 12), "não havia nesse contexto, a intenção de transformação social do indivíduo por meio da reflexão". O objetivo era acabar com o analfabetismo em dez anos. Em 1970, com objetivo de um custo mais acessível, criou-se o Supletivo.

Com um custo operacional mais barato, e com finalidade de preparar o indivíduo para o mercado de trabalho mais competitivo e exigente, implementou-se, na década de 1970, o Ensino Supletivo com uma política que objetivava escolarizar um maior número de pessoas em todo o território nacional. (CORTADA, 2013, p. 12).

Até meados da década de 80, o Mobral não parou de crescer, atingindo todo território nacional e diversificando sua atuação, mas 1985 foi extinto o Mobral e substituído Saberes Pedagógicos, Criciúma, v. 3, n³, Edição Especial 2019.- Curso de Pedagogia - UNESC 
pela Fundação Educar. Segundo Cortada (2013, p. 12), "nesta substituição o que marcou foi a retomada da Educação de Jovens e Adultos e exerceu a função de supervisionar e acompanhar as instituições que recebiam os recursos transferidos para o programa".

Em 1988 o país reconhece que é dever do estado a Educação de Jovens e Adultos. “[...] Em 1988 a Carta Magna do país reconhece que são deveres do Estado a gratuidade e universalidade de acesso das pessoas jovens e adultas à Educação Fundamental" (CORTADA, 2013, p. 13).

Em 20 de dezembro de 1996 o então Presidente da República Fernando Henrique Cardoso sancionou a lei 9.394, a qual estabeleceu as Diretrizes e Bases da Educação Nacional. Esta Lei veio para organizar a educação em âmbito nacional, contemplando a educação de jovens e adultos na Seção V, os Arts. 37 e 38 são específicos para Educação de Jovens e Adultos (EJA), que ao longo dos anos subsequentes sofreu alteração em sua redação conforme o texto a seguir:

\footnotetext{
Da Educação de Jovens e Adultos:

Art. 37. A educação de jovens e adultos será destinada àqueles que não tiveram acesso ou continuidade de estudos nos ensinos fundamental e médio na idade própria e constituirá instrumento para a educação e a aprendizagem ao longo da vida. (Redação dada pela Lei $n^{\circ} 13.632$, de 2018)

$\S 1^{\circ}$ Os sistemas de ensino assegurarão gratuitamente aos jovens e aos adultos, que não puderam efetuar os estudos na idade regular, oportunidades educacionais apropriadas, consideradas as características do alunado, seus interesses, condições de vida e de trabalho, mediante cursos e exames.

$\S 2^{\circ} \mathrm{O}$ Poder Público viabilizará e estimulará o acesso e a permanência do trabalhador na escola, mediante ações integradas e complementares entre si.

§ 3ㅇ A educação de jovens e adultos deverá articular-se, preferencialmente, com a educação profissional, na forma do regulamento. (Incluído pela Lei $\mathrm{n}^{0} 11.741$, de $\underline{2008)}$

Art. 38. Os sistemas de ensino manterão cursos e exames supletivos, que compreenderão a base nacional comum do currículo, habilitando ao prosseguimento de estudos em caráter regular.

$\S 1^{\circ}$ Os exames a que se refere este artigo realizar-se-ão:

I - no nível de conclusão do ensino fundamental, para os maiores de quinze anos;

II - no nível de conclusão do ensino médio, para os maiores de dezoito anos.

$\S 2^{\circ}$ Os conhecimentos e habilidades adquiridos pelos educandos por meios informais serão aferidos e reconhecidos mediante exames.
}

O Ministério da Educação e Cultura em 2003 anunciou o PBA (Programa Brasil Alfabetizado), que seria uma prioridade do Governo Federal, tendo como fim a tentativa de erradicar o analfabetismo no país. Tal programa tinha como finalidade alfabetizar cidadãos de

Saberes Pedagógicos, Criciúma, v. 3, n³ 3, Edição Especial 2019.- Curso de Pedagogia - UNESC 
15 anos ou mais, que não tiveram chances de estudar ou retirados da escola antes de aprender a ler e escrever. Vale a pena ressaltar que esse programa incluía população indígena, rural, deficiente, pescadores e carcerários, dentre outros indivíduos.

Percebe-se, nos dias atuais, que esta modalidade de ensino está garantida nas leis, propostas pedagógicas são elaboradas e discutidas a nível nacional, estadual e municipal, com o principal objetivo de incluir estes alunos na sociedade, mas cabe aos professores se perguntarem se, de fato, todos aqueles que frequentam estas salas de aula usufruem dos direitos que a sociedade lhes garante.

\section{ESCOLA E SOCIEDADE}

Quando se fala em escola, as pessoas logo se remetem àquela que habita as lembranças pessoais. Não é apenas a estrutura física que é lembrada, mas os espaços, os colegas, os professores e, por que não dizer, algumas fases da vida. A escola das lembranças está inserida num mundo que não é mais o mesmo e as pessoas também não, pois a sociedade está em constante transformação.

Portanto, a escola não pode ficar estática no tempo, tem que caminhar junto, em busca de uma educação inovadora e de qualidade. Esta educação só pode ocorrer em uma escola que, segundo Silva (2004, p. 29), “[...] torne seus espaços e lugares, de fato, em educativos, seus momentos em tempos de formação humana [...] Uma escola que nos convide que inclua-nos, seduza-nos e encante-nos".

Assim sendo, a escola deve ser encantadora para que seus alunos sintam-se motivados a estudar; deve ser formadora, comprometida com a apropriação do conhecimento e habilidades significativas dos seus alunos, a fim de torná-los cidadãos presentes e atuantes, na construção de uma sociedade participativa e democrática. O cotidiano escolar, assim comprometido, oportuniza a vivência da

[...] cidadania, na compreensão da realidade, no exercício da liberdade e da responsabilidade, na intenção e no interesse pelo outro, no respeito pela diversidade, na correta tomada de decisões, no comprometimento com as condições de desenvolvimento humano, social e ambiental. (ALARCÃO, 2001, p. 22). 


\section{SABERES PEDAGÓGICOS}

Revista do Curso de Graduaçāo de Pedagogia - Unesc

ISSN $2526-4559$

Portanto, as escolas devem levar em conta as características dos alunos e de seu meio, visando ao desenvolvimento de novos valores voltados à reconstrução social, ou seja, a formação de um sujeito crítico, reflexivo que interage no meio social de maneira consciente. Gadotti (2000, p. 142) enfatiza esta ideia dizendo que "Escola cidadã é aquela que [...] forma o cidadão completo, competente e solidário, não apenas o cidadão competitivo [...]”.

Paulo Freire, professor, grande pesquisador brasileiro, autor de vários livros, destacou-se por fazer parte dos que, como ele, lutavam e lutam por uma escola inovadora, transformadora. Em seus livros deixou um legado de sabedoria, neles encontram-se afirmações que levam à reflexão sobre a escola pela qual todos devem lutar. Ou seja, "a escola que é aventura, que é marcha, que não tem medo do risco, por isso que recusa o imobilismo. A escola em que se pensa, em que se fala, em que se ama, se adivinha, a escola que apaixonadamente diz sim à vida" (FREIRE, 2002, p. 63).

A escola que a sociedade necessita é a que cumpre sua função em prol de uma educação transformadora, uma escola que seja para todos, que torne as pessoas autônomas, que se preocupe em formar sujeitos interativos e conscientes, enfim, uma escola que vise a uma sociedade democrática e justa para todos. "Evidentemente, essa escola não será construída de um dia para o outro, não se chegará rapidamente, nem por um passo de mágica [...] Não adianta alguns poucos chegarem lá muito rapidamente. É preciso que todos cheguem lá em tempo" (GADOTTI, 2000, p. 142).

Para chegarmos lá todos juntos, precisamos de uma peça chave: o professor. A imagem que vem à cabeça ao falar de escola é aquela das lembranças pessoais, ao falar dos professores não será diferente. Por isso faz-se a seguir uma reflexão sobre a formação do professor, a base para uma educação de qualidade e para uma escola inovadora.

\section{O PROFESSOR E O ESPAÇO DA EJA}

A escola é o ambiente de trabalho do profissional da educação, contudo acreditase que ser professor ultrapasse o significado da palavra trabalho, é ter uma missão a cumprir, é ter a certeza do que se quer, é ter amor pelo que se faz em prol do ser humano. 
É missão, no sentido de ser uma meta, uma intencionalidade, ou seja, o professor precisa saber o que quer e onde pretende chegar. É uma missão gratificante, porém, ao mesmo tempo difícil e complexa. Conforme Freire (2000, p. 11), "o processo de ensinar, que implica o educar e cuidar e vice-versa, envolve a paixão de conhecer que nos insere numa busca prazerosa, ainda que, nada fácil”.

Acredita-se que uma boa formação do professor começa pelo comprometimento com o ensino, motivado pela alegria de ensinar, pois esta alegria é capaz de estimular alunos e professores a compreenderem a importância do significado e o sentido dos conteúdos a serem trabalhados nas aulas. Alves (2000, p. 12-13) questiona essa atitude docente quando escreve:

\begin{abstract}
[...] será que vocês não percebem que as disciplinas que vocês devem ensinar, nada mais são que taças multiformes coloridas, que devem estar cheias de alegria? Pois o que vocês ensinam não é deleite para a alma? Se não fosse, vocês não deveriam ensinar. E se é, então é preciso que aqueles que recebem, seus alunos, sintam prazer igual ao que vocês sentem. Se isto não acontecer, vocês terão fracassado na sua missão, como a cozinheira que queria oferecer prazer mas a comida saiu salgada ou queimada...
\end{abstract}

Percebe-se que a alegria é fundamental ao ensino. Alegria de ensinar não significa facilidade ou simplificação do processo, mas um anseio em proporcionar aos alunos o desejo de aprender e a satisfação de ter aprendido.

Para o professor da educação de jovens e adultos, torna-se indispensável que se desprenda de estigmas, de preconceitos, de representações sociais pré-estabelecidas, acreditando nisso, que invista em práticas educativas personalizadas em seu público-alvo. Para Lima (1991, p. 56):

\begin{abstract}
Se os professores compreendem que um determinado método pedagógico, como o trabalho diversificado, pode reduzir imensamente os problemas de heterogeneidade nas classes, e se compreendem que heterogeneidade é um fenômeno que aparece em qualquer classe independente da classe cronológica, certamente abandonam os métodos clássicos, onde o professor 'recita uma aula' para um conjunto abstrato, supondo uma homogênea compreensão, e passam a trabalhar por atividades graduadas conforme o nível de cada subgrupo de sua classe.
\end{abstract}

Para a autora, cabe ao educador desenvolver um planejamento flexível e consistente que planeje estratégias variadas de ensino, possibilitando situações de 
aprendizagens desafiadoras, que sejam de fato pertinentes aos níveis sociocognitivos dos alunos.

Na sala de aula, ao possibilitar situações desafiadoras o professor age como mediador dos diferentes saberes. A função docente fundamental é a mesma para todos os segmentos educacionais. Ensinar passa a ser a busca por fazer alguém aprender algo, fazendo o papel de intermediário entre conhecimento e sujeito- aprendiz (CORTADA, 2013).

A autora ainda afirma que:

\begin{abstract}
A EJA é considerada um segmento de compassos e descompassos, encontros e desencontros, idas e vindas, A experiência profissional, vivida pelo professor no dia a dia é permeado de significados, oportunizando ao docente transformar sua prática e transformar-se nela. Mas isso só será possível se ele aceitar seu papel de agente transformador da sociedade e realizar exercício permanente de auto observação, auto análise e autocrítica. (CORTADA, 2013, p. 30).
\end{abstract}

Esta afirmação nos leva a pensar que o fazer pedagógico depende da mudança da forma de olhar para si, para o outro e para o entorno e que modificar o modo de pensar oportuniza construir um outro conceito de educação. A respeito desta afirmação Freire (1996) corrobora dizendo que ensinar exige comprometimento e isso possibilita uma mudança interna no sujeito. $\mathrm{O}$ autor fala também que, quando o professor se coloca em frente ao aluno, se expõe, se predispõe, se revela com facilidade ou relutância. E afirma:

\footnotetext{
Não posso escapar à apreciação dos alunos. E a maneira como eles me percebem tem importância capital para o meu desempenho. Daí, então, que uma das minhas preocupações centrais deva ser a de procurar a aproximação cada vez maior entre o que pareço ser e o que realmente estou sendo. Saber que não posso passar despercebido pelos alunos, aumenta minha tarefa de professor. (FREIRE, 1996, p. 108).
}

Esta fala de Freire contribui para o papel do professor da EJA. Por ser atuante em uma modalidade de ensino definida de grande diversidade, a EJA exige do professor uma tomada de consciência aberta do mundo, do segmento, dos alunos e da própria educação. Sendo assim, este professor necessita se apropriar do verdadeiro entendimento de sua responsabilidade, da sociedade que deseja construir frente aos seus alunos. 


\section{SABERES PEDAGÓGICOS}

Revista do Curso de Graduaçāo de Pedagogia - Unesc

ISSN 2526-4559

Percebe-se na fala do autor que o professor jamais passa despercebido pelos alunos e que a maneira como eles o percebem pode ajudar ou não no cumprimento da sua tarefa de professor.

\section{EJA: JOVENS E ADULTOS: IDAS E VINDAS}

A educação de Jovens e Adultos é uma modalidade de ensino com o objetivo de conceber que jovens, adultos e idosos que não tiveram a chance de frequentar a escola na idade correta possam retomar seus estudos e se alfabetizar. Devido às novas tecnologias o mercado de trabalho tem avançado rapidamente, o trabalhador analfabeto luta para subsistir.

Segundo Cortada (2013, p. 7):

Definida como Educação de Jovens e Adultos, EJA é uma modalidade de Educação Básica cujo objetivo é o de favorecer oportunidades de estudo a essa parcela da sociedade que não teve acesso aos estudos na idade própria.

Compreender o EJA se faz necessário, devido à sua importância no cenário educacional como instrumento de inclusão da fração da sociedade cujas oportunidades foram subtraídas por efeito da situação política, econômica, social ou cultural do país.

Assim se faz necessário saber que o aluno do EJA tem como perfil, na sua maioria, trabalhadores, donas de casa, desempregados, jovens, adultos, idosos, portadores de deficiência, ou seja, são perfis distintos. Eles na maioria das vezes tiveram suas trajetórias escolares interrompidas, pela necessidade de trabalhar, ajudar na casa, tinham enraizados em sua cultura que o sustento de sua família vinha antes da alfabetização. "Isso significa que no estado adulto as pessoas sabem que suas decisões afetam suas vidas. Incorporam suas responsabilidades e assumem as consequências dos seus atos" (CORTADA, 2013, p. 61).

A sociedade tem já por rotina vários afazeres, os quais dependem da escrita e da leitura. Os exemplos mais básicos são: para fazer compras tem que conhecer os números, elaborar a lista; para se tomar um ônibus é necessário conseguir identificá-los, contudo, esse aluno que por algum motivo não pode estudar, pode se sentir excluído da sociedade. Assim remetemos ao pensamento de que quando pensamos exclusão logo nos vem à cabeça pessoas com deficiências físicas, mas não, a exclusão não se limita só às deficiências físicas, mas sim 
as intelectuais e mentais também. Para Cortada (2013, p. 64), "os adultos entendem que o que aprendem pode ser usado agora e lhes permitirá maior assertividade na resolução de seus problemas cotidianos".

Grande parte dos jovens e adultos que retornam à escola tem essa necessidade de se sentir incluso na sociedade, almejando sempre melhores condições de vida, um melhor cargo de trabalho. Muitos deles visam ao domínio da escrita, da leitura e tendo como alvo serem mais críticos e participativos na sociedade, porém, boa parte deles busca mesmo é uma realização pessoal.

Uma vez que estes alunos da EJA vão para a escola após um longo dia de trabalho, suas mentes já estão cansadas, logo, o aluno da EJA possui necessidade educacional especial, independente de ter ou não deficiência. Arroyo (2003, p. 7) nos leva a refletir sobre este público-alvo que frequenta a EJA quando diz:

O campo da EJA está se firmando de maneira muito intensa, com sua especificidade, com suas dificuldades próprias e também com suas deficiências que precisam ser vencidas. Os alunos da EJA chegam a escola não "desencantados" com a educação, mas sim carregados de saberes, vivência, cultura, valores, visões de mundo e de trabalho.

Assim, a fala do autor nos remete a acreditar que a quase totalidade desses indivíduos pertencem à esfera socioeconômica da exclusão e retorna à escola na busca de um sonho, de uma vida melhor, no desejo de conseguir um trabalho de remuneração mais digna, uma independência de vida ou pelo simples prazer de voltar a frequentar a escola que um dia ficou para trás.

Tem que ser trabalhada a realidade do aluno, sua vivência, e principalmente da sua família e trabalho. Para Cortada (2013, p. 186), "ao trabalhar com ênfase na cultura local, na realidade vivida, a educação se torna elemento transformador e de conscientização". Assim a educação transforma vidas, pois o aluno vai do analfabetismo a uma pessoa que aprendeu a ler e escrever, podendo assim ter novas chances e oportunidades. "A cultura que este educando, até então, teve suplantada por relações de poder que o oprimiam e o colocavam em situação de não (re) conhecimento, se traduz em ferramenta essencial para libertar-se e modificar a situação de opressão" (CORTADA, 2013, p. 186).

Saberes Pedagógicos, Criciúma, v. 3, n³, Edição Especial 2019.- Curso de Pedagogia - UNESC 
Para auxiliar e principalmente para que o aluno entenda o que é trabalhado pelo educador, deve utilizar diálogos, falas que facilitem a compreensão, facilitando assim um constructo teórico e pessoal maior. Cortada (2013, p. 188) diz que "[...] ao lidarmos com alunos de EJA, precisamos propor diálogos que facilitem suas aprendizagens e tais diálogos melhor se constituem dentro do contexto dos que se encontram envolvidos [...]".

Refletindo sobre a EJA no Estado de Santa Catarina, no ano de 1998 foi elaborada a Proposta Curricular de Santa Catarina Temas Multidisciplinares uma parceria entre a Secretaria de Estado da Educação e a Universidade Federal de Santa Catarina e professores da rede estadual de ensino. Nela, foram dedicadas algumas páginas para a EJA.

Neste sentido destacamos a afirmação que fala sobre o regresso deste aluno à escola:

Os jovens e adultos retornam à escola motivados pelas mais diversas razões: o sonho de conquistar melhores salários, a ameaça do desemprego, a necessidade de contribuir mais eficazmente na formação dos filhos, a realização pessoal, entre outros são fatores de peso neste processo. A própria angústia existencial do ser inconformado, buscando sempre novas respostas para os seus problemas, muito contribui para a volta à escola. (SANTA CATARINA, 1998, p. 38).

Para se repensar no destino da educação de jovens e adultos, tem que se buscar entender o grupo e suas diferentes culturas, como eles reagem às teorias que são propostas, utilizando linguagens acessíveis e de fácil entendimento, para que assim o aluno que vai à aula cansado depois de um dia de trabalho sinta prazer em estar lá, e que sinta também um crescimento pessoal e profissional.

\section{METODOLOGIA, APRESENTAÇÃO E ANÁLISE DE DADOS}

O presente trabalho se constitui em uma pesquisa de campo do tipo exploratória, com abordagem qualitativa. Segundo Gil (1991), o objetivo dessas pesquisas é possibilitar a proximidade com o problema, tornando-o explícito e aperfeiçoando determinadas ideias ou descobertas.

Inicialmente, para fundamentar as discussões aqui realizadas fez-se um estudo teórico para melhor compreender sobre o tema proposto. A partir do estudo teórico realizou-se uma 


\section{SABERES PEDAGÓGICOS}

Revista do Curso de Graduaçāo de Pedagogia - Unesc

ISSN 2526-4559

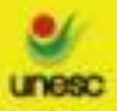

wationstion

pesquisa de campo por meio de entrevistas semiestruturadas com alunos que frequentam uma escola no município de Criciúma/SC que oferece a EJA no turno noturno.

A amostra foi intencional e foram entrevistados oito alunos, quatro do ensino fundamental (anos iniciais) e quatro dos anos finais, que por razões éticas serão representados pelas letras do alfabeto: A, B, C, D, E, F, G e H. No primeiro momento das entrevistas eles ficaram um pouco inseguros para falar sobre o tema, porém iam se sentindo mais à vontade no decorrer do processo. Os dados coletados na pesquisa de campo foram agrupados pelas questões da entrevista e serão apresentados, seguidos da análise teórica.

A primeira questão da entrevista versava sobre a identificação dos sujeitos. Os oito alunos pesquisados têm idade entre 18 e 60 anos, sendo cinco do sexo feminino e três do sexo masculino. Três alunos frequentam a turma de alfabetização, um a quinta série e quatro os anos finais do ensino fundamental ( $8^{\circ}$ e $9^{\circ}$ anos).

A maioria dos entrevistados mora com seus respectivos maridos ou esposa e filhos, exceto a aluna $\mathrm{D}$, que reside com os filhos e a mãe, e a aluna $\mathrm{E}$, que mora na casa da sogra. A renda familiar varia em torno de um a dois salários mínimos.

Ao serem questionados se haviam frequentado alguma escola quando crianças, foram unânimes ao responder que sim. Por exemplo, a aluna A: "Sim, fui até a segunda série". E a aluna F até o final da sétima série.

Constatou-se que os alunos da turma de alfabetização passaram menos tempo na escola, ao contrário dos demais entrevistados, que pelo menos quase concluíram os anos finais do ensino fundamental.

Quando questionados a respeito da escola em que estudavam, a maioria disse ser boa. No entanto, cada um explicou o que significava a expressão "ser boa". A aluna A respondeu: "Os professores ensinavam bem a gente". O aluno afirmou: "os professores puxavam bastante, era uma escola forte". Analisando suas explicações, percebe-se que o fato da escola ser boa estava relacionado à atitude dos professores.

É interessante observar que mesmo quando o aluno não aprendia não culpava o professor. Esta visão foi reforçada com a fala da aluna F ao afirmar: "As professoras eram boas, eu que era muito burrinha mesmo. Eu gostava de estudar, só que não conseguia aprender”.

Já os alunos B e C se detiveram mais ao contexto escolar. "Me lembro que as carteiras eram de dois lugares, de madeira escura e a professora era morena e baixinha" (aluno B).

Saberes Pedagógicos, Criciúma, v. 3, n³, Edição Especial 2019.- Curso de Pedagogia - UNESC 
"Era muito simples, pobrinha, era uma escola mais do interior, a gente não tinha muita coisa lá não" (aluna C).

Percebe-se por meio desses depoimentos que a escola descrita pelos entrevistados ainda esta distante de ser vista como a instituição formadora e encantadora que se compromete com o desenvolvimento de seus alunos. Em nenhum momento fizeram relação entre a escola e a vida em sociedade. A experiência deles enquanto alunos não os formou para a cidadania, não os fez ver que "a educação escolar tem um papel fundamental nesse processo de socialização, de construção de subjetividades individuais e coletivas, numa dinâmica de encantamento, de nascimento social" (SILVA, 2004, p. 31).

Sobre a metodologia utilizada pelos professores que os ensinavam, os entrevistados responderam o seguinte: "Ela explicava, só que se a gente não entendesse ela não ia até a carteira explicar de novo. Deus nos livre de perguntar" (aluna G). A aluna D respondeu: "Eles ensinavam bem, a disciplina era bastante cobrada, o professor sabia tudo e ensinava para nós".

Analisando estas falas, percebe-se que a prática do professor era tão rigorosa que os alunos tinham medo de perguntar, não existia aproximação entre professor e aluno. É interessante ressaltar que essa de metodologia era entendida como boa, pois nenhum dos entrevistados relatou que era ruim.

Felizmente percebe-se que com o passar dos anos o conceito de professor muda. O tipo de professor descrito pelos pesquisados não é considerado bom nos dias de hoje, pelo contrário. $\mathrm{O}$ bom professor é aquele que torna as aprendizagens significativas, que estimula a curiosidade, a pesquisa e que media o conhecimento de seus alunos.

Ao possibilitar situações inovadoras e problematizadoras, o professor age como mediador da aprendizagem, estimulando o pensamento crítico e criativo, formando cidadãos autônomos e transformadores da sociedade em que vivem.

Nesse novo contexto, o professor não é tanto o transmissor do conhecimento, mas aquele que seleciona a informação e apresenta-a de forma crítica. Ele se tornou um mediador, um articulador e formador de capacidades. Por sua vez o aluno precisa de autonomia intelectual para formular propostas e para utilizar diferentes meios de informação. (GADOTTI, 2000, p. 144). 


\section{SABERES PEDAGÓGICOS}

Revista do Curso de Graduaçūo de Pedagogia - Unesc

ISSN $2526-4559$

A verdadeira chave do sucesso é definir estratégias capazes de fazer a diferença e garantir que o aluno consolide os conteúdos desenvolvidos em sala de aula e avance na aprendizagem. Mas para isso é preciso que o professor esteja sempre aberto às inovações que ocorrem na sociedade.

Em relação aos motivos que os levaram a parar de estudar, os entrevistados destacaram algumas causas da desistência escolar, como: “A minha casa era longe da escola naquele tempo o importante era trabalhar na lavoura para ajudar a família. $\mathrm{O}$ estudo não era importante como hoje" (Aluno F); "Comecei a trabalhar muito cedo, a minha família era muito pobre e não incentivavam ir para a escola, a gente tinha que se virar para comer" (aluna D); “Eu não entendia como a professora explicava, tinha medo de perguntar, em casa ninguém sabia me ensinar, daí desanimei e fui ajudar em casa a cuidar dos meus irmãos mais novos e depois fui pra roça” (Aluna $\mathrm{H}$ ).

Refletindo sobre as falas dos entrevistados sobre os motivos que desistiram da escola percebemos que o trabalho influenciou diretamente a vida destas pessoas, ou seja, o estudo não era importante, por isso a família não exigia que frequentassem a escola. Outro fator decisivo foi o econômico, que desde muito cedo os levou para o trabalho para ajudar na renda familiar. Isso vem reforçar a hipótese apontada no referencial teórico de Marchesi e Péres (2004), sobre as condições sociais serem uma das causas da exclusão escolar.

As condições sociais em que viviam os entrevistados eram precárias, eram de famílias pobres. Este fator ocasionou a busca de um trabalho para o qual não precisa ter estudo. Certamente este motivo jamais levaria uma pessoa da classe alta a desistir dos estudos. Segundo Perrenoud (1999, p.71), “os alunos melhor dotados em capital cultural e melhor acompanhados por suas famílias seguirão, de qualquer maneira, seu caminho".

Contudo, ressalta-se que em alguns casos o desinteresse pode ser oriundo da ação docente, como a fala da aluna $\mathrm{H}$. Dessa forma, percebe-se que a prática docente era marcada por uma disciplina rígida: de medo e silêncio, mediação, construção. Esse professor seguia seu programa, ignorava o aluno, o qual era visto como um ser passivo, sem conhecimento. Essa prática docente pouco entendia sobre aprendizagem, mediação, construção do conhecimento, motivo esse que levou muitos alunos a se afastarem da escola. 
Segundo Cortada (2013, p. 7), “compreender o que é a EJA se faz necessário, devido à sua importância no cenário educacional como instrumento de inclusão da fração da sociedade cujas oportunidades foram subtraídas por efeito da situação política, econômica, social ou cultural do país”. Já para Lima (1991, p. 15), “o trabalho de alfabetização de adultos é, sem dúvida, importante às organizações populares que acreditam na necessidade de formação, para que o povo seja agente de sua própria história".

Ao serem questionados sobre os motivos que os levaram a voltar a estudar, notou-se que foram vários e de certa forma muito importantes como se pode observar:

"Me sentia envergonhada por não saber ensinar meus filhos nas tarefas de casa"(aluna B).

"Pra ir no Banco receber meu pagamento e não precisar de ajuda de ninguém no caixa" (aluno A).

"Quero tirar minha carteira de motorista"(aluno D).

"Para poder pegar o ônibus, ir no mercado, ler as propagandas, é muito triste não saber ler. Quem não sabe ler não é ninguém na vida" (Aluna C).

"Por causa do meu emprego, tem que ter o ensino médio. O patrão cobra o estudo" (aluno F).

"Quero progredir no meu trabalho, ganhar mais, por isso voltei pra escola" (aluno H).

“Sem o $2^{\circ}$ Grau agente não encontra um trabalho melhor e quero ser alguém na vida" (aluna E).

"Quero ser a chefe no meu emprego,sou cozinheira a muito tempo, mas sem estudo não consigo ser, mesmo sabendo cozinhar muito bem” (aluna G).

Analisando as respostas, pode-se constatar que os alunos que estão na turma de alfabetização (anos iniciais do enfino fundamental) voltaram á escola por motivos relacionados a sua autonomia. Principal motivo foi aprender ler e escrever . Já os alunos das séries mais avançadas, retornaram por razões mais profissionais e de auto-estima, querem ser alguém na vida. Paiva (1997 apud SANTA CATARINA,1988, p. 42) se refere a estes alunos dizendo que " [...] a EJA deve ser um espaço de encontros, onde estes alunos 


\section{SABERES PEDAGÓGICOS}

Revista do Curso de Graduaçāo de Pedagogia - Unesc

ISSN 2526-4559

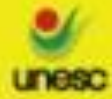

Thtiminges

possam falar de si, de suas experiências. Onde sejam reconhecidos e valorizados como pessoas, como trabalhadores com uma função digna".

A EJA, modalidade de ensino que trabalha com estes sujeitos, não pode esquecer que eles estão voltando a segunda vez para a escola, não são mais crianças, mas jovens , adultos e até idosos em busca de desejos e esperança de uma vida melhor.

\section{CONCLUSÃO}

A narrativa da Educação de Jovens e Adultos no Brasil transformou-se muito durante o passar dos anos no Brasil e assim acompanhou as variações sociais, políticas e econômicas do país, sempre ensejando o ensino de qualidade. Porém, as lutas não acabaram, elas continuam intensas e amplas, para manter-se este sistema de ensino e erradicar o analfabetismo.

Neste trabalho de pesquisa buscou-se identificar que fatores foram decisivos para que os jovens/adultos não frequentassem a escola em período adequado e o que os motivou a reingressarem. Após a entrevista realizada com os alunos que frequentam uma escola da EJA, por meio da análise realizada, foi possível apontar as causas da desistência escolar. Dentre as quais destacaram-se: as condições sociais em que viviam que os levou a trabalhar desde cedo para ajudar na renda da família; a falta de motivação familiar; o desinteresse do aluno; a ação docente tradicional; a falta de um sistema docente comprometido com a educação, além da falta de consciência que tinham sobre a importância do estudo para a vida. Essas causas vieram confirmar que, segundo os teóricos estudados, a responsabilidade do fracasso escolar é multidimensional.

Os entrevistados relataram nas suas falas que a escola era boa. No entanto, fizeram afirmações que levam a pensar o contrário. Descreveram que os professores "puxavam" bastante, porém reclamaram que não iam até a carteira para explicar de novo a matéria e que os alunos tinham medo de perguntar o que não entendiam. Percebeu-se ser uma escola em que não havia aproximação entre os alunos e os professores, uma escola marcada pela lei do medo e do silêncio. 
A respeito dos motivos do reingresso escolar pode-se se destacar que os alunos da turma de alfabetização voltaram à escola por motivos relacionados à sua autonomia. Já os alunos das séries mais avançadas retornaram por razões profissionais, para conseguir um trabalho de maior remuneração, para aumentar a autoestima, querer ser alguém na vida. Observou-se que a questão relacionada ao trabalho no passado os afastou da escola, movidos por precárias condições sociais, agora o mesmo motivo os levou a voltar, em busca de uma oportunidade de vida melhor.

Diante disso conclui-se que a escola precisa assumir cada vez mais seu papel na sociedade, eliminar a evasão escolar, para que no futuro não se tenha mais jovens e adultos sem escolarização. O sistema educacional deve garantir e efetivar uma educação inclusiva que chegue a todos e em todo território nacional, e o professor tem que estar cada vez mais preparado para enfrentar os desafios da educação.

Desse modo se faz necessária a reflexão das práticas pedagógicas desenvolvidas nas escolas e também um maior investimento na formação docente, visando formar cidadãos críticos e reflexivos, construtores e autores da sua história. Minha pretensão com esta pesquisa não é dar o assunto por encerrado, mas sim abrir caminhos para que se possa refletir sobre a EJA por todos os envolvidos no processo de ensino e aprendizagem.

\section{REFERÊNCIAS}

ALARCÃO, Isabel. Escola reflexiva e nova racionalidade. Porto Alegre: Artmed Editora, 2001.

ALVES, Rubem. Entre a ciência e a sapiência: o dilema da educação. 4. ed. São Paulo: Loyola, 2000.

ARROYO, Miguel G. Pedagogias em movimento: o que temos a aprender dos movimentos sociais? Currículo sem Fronteiras. v. 3, 2003.

BRASIL. Presidência da República, Casa Civil. http://www.planalto.gov.br/civil_03/leis/L9394.htm . Acesso em: 10 Março 2018:

CORTADA, Silvana (org.). EJA: Educação de jovens e adultos e seus diferentes contextos. Jundiaí, SP: Paco, 2013. 200 p. (Pedagogia de A a Z; v. 12).

FREIRE, Paulo. Pedagogia da autonomia: saberes necessários à prática educativa. 13. ed.

Saberes Pedagógicos, Criciúma, v. 3, n³, Edição Especial 2019.- Curso de Pedagogia - UNESC 
Rio de Janeiro: Paz e Terra, 1996.

Pedagogia do oprimido. 31. ed. Rio de Janeiro: Paz e Terra, 2001. 184 p.

Pedagogia da esperança. 13. ed. Rio de Janeiro: Paz e Terra, 2006.

GADOTTI, Moacir. Perspectivas atuais da educação. Porto Alegre: Artes Médicas, 2000.

GIL, Antonio Carlos. Como elaborar projetos de pesquisa. São Paulo: Atlas, 1991.

LIMA, Adriana Flávia de Oliveira. Alfabetização de jovens e adultos e a reconstrução da escola. Petrópolis, RJ: Ed. Vozes, 1991, 227 p.

BRASIL. MINISTÉRIO DA EDUCAÇÃO. Programa Brasil Alfabetizado.

http://portal.mec.gov.br/programa-brasil-alfabetizado. Acesso em: 05 Mar. 2018.

PERRENOUD, Philippe. MAGNE, B. C. Construir: as competências desde a escola. Porto Alegre: Artmed, 1999.

SANTA CATARINA. Ministério da Educação e Cultura/Secretaria de Ensino Fundamental. 2. ed. Educação para Jovens e Adultos. Ensino Fundamental. Proposta Curricular para o $1^{\circ}$ Segmento. São Paulo: Ação Educativa; Brasília: MEC, 1998.

SILVA, Janssen Felipe. Avaliação na perspectiva formativa-reguladora, pressupostos teóricos e práticos. Editora Mediação, 2004. 